\title{
Complexity Leadership: On time, on budget.
}

This paper was downloaded from TechRxiv (https://www.techrxiv.org).

\section{LICENSE}

CC BY 4.0

SUBMISSION DATE / POSTED DATE

13-02-2022 / 22-02-2022

\section{CITATION}

Biggadike, Chris; Pei, Eujin; Evans, Richard (2022): Complexity Leadership: On time, on budget.. TechRxiv. Preprint. https://doi.org/10.36227/techrxiv.19165913.v1

$\mathrm{DOI}$ 


\title{
Complexity Leadership: On time, on budget.
}

\author{
Chris Biggadike Member, IEEE. Richard Evans Member IEEE. Eujin Pei.
}

\begin{abstract}
Keywords - Complexity Leadership; Adaptive Leadership; Enabling Leadership; Administrative Leadership.
\end{abstract}

\begin{abstract}
In complex organizations, such as large international engineering firms, practicing managers may possess administrative, enabling and adaptive leadership styles. Each of these leadership styles must be balanced, but Key Performance Indicators (KPI) can drive imbalance in engineering management projects. We provide practicing managers with some insights to these leadership styles and their interaction to understand their benefits and challenges that may be overcome. Further, we present a "balance check" that outlines symptoms of leadership imbalance to keep things from going awry.
\end{abstract}

\section{INTRODUCTION}

Complexity Leadership Theory (CLT) links complexity science to an understanding of managing organizations. CLT can be applied at any scale from small team activities to interbusiness programs. It is rooted in the premise that organizations behave as complex systems. CLT can help engineering managers understand and nurture innovation, while delivering business performance - especially within a project's environment. For engineering projects, a core responsibility of engineering managers is to maintain schedules and budgets. On project completion, success will hinge on meeting expectations - often in the form of key performance indicators [1,2]. Schedule and budget KPIs form the cornerstone of many engineering management processes, interactions and behaviors. Competitive pressures mean that hitting these targets, while delivering a technically compliant solution, is something of a black art and any method which might improve the success rate, commonly cited as between $25 \%$ and $45 \%$ [3], is worthy of serious consideration.

Engineering project teams commonly comprise two factions: a team of engineers in a state of fluid technical development and a management team that aims to maintain order, making decisions, and ultimately appropriate progress. The management team helps brings structure in the form of planning, process, administration and governance. In one model of this relationship, there exists a "healthy tension" between them and the technical engineering team who are, in turn, trying to solve technical challenges within the constraints of the project. In the no-man's-land of compromise which exists between these two tribes - sometimes with conflicting goals and priorities - the project is delivered. Whichever mental model is used to frame the relationship between the leaders and the led, the reality of tracking schedule and cost, juxtaposed with the creative process, frequently means a bumpy ride on the road to success. CLT proposes that a shift in perspective is required to effectively lead complex activities such as engineering projects. Many organizations-especially larger ones - have a variety of intertwined complex elements, including people, suppliers, customers, the global market, software tools, resource pools and multiple stakeholders, causing greater uncertainties and risks. On the one hand, this complexity means that our plans, models, and forecasts are, very likely, not accurate. Alternatively, opportunity, innovation, and creativity, may arise from this uncertainty and organizational cacophony. Such events being the very things that bring competitive advantage and survival of the organization. In this article, we propose a balanced approach for managers in which the three styles of leadershipadministrative, enabling, and adaptive - are recognized and deployed [4]. This recognition and deployment are a starting point for understanding the applied fundamentals of CLT, with its origins rooted in the fundamentals of complex system behavior.

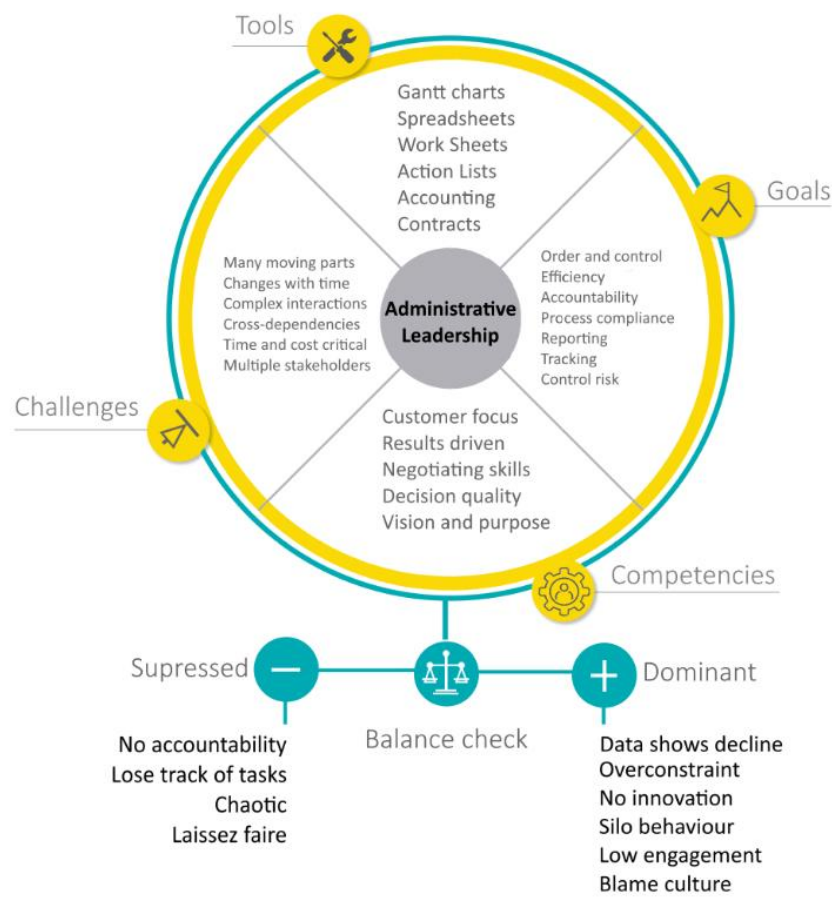

Fig. 1 Administrative Leadership Model

\section{ADMINISTRATIVE LEADERSHIP}

In engineering management, a substantial portion of the "heavy lifting" occurs through a partnership of administrative and enabling leadership. Administrative leadership comes in the form of planning, recording, reporting, accounting, and 
associated processes and methods. These items provide consistency of communication, clarity of purpose and an overall sense of where we are versus where we need to be. Four facets of administrative leadership, plus a "balance check" are outlined in Fig. 1 which is synthesized from both CLT and feedback from within firms.

The overarching purpose of this leadership style is to reduce a team's cognitive burden. If done well, administrative leadership allows the project team to focus on the technical challenges at hand, while doing enough administrative work to maintain schedule and cost. Of course, if the administrative leader burdens the team with high levels of administrationprocesses in constant flux, training for new tools, microreporting etc. - then administration becomes a burden rather than a tool. With administrative dominance, the team will find themselves in a state of unproductive and inefficient distraction. In this instance, it is easy to end up in a state of administrative overload. This can arise from pressures stemming from business uncertainty; the strong smell of risk is a powerful motivator for administrative burden. This situation often results in reams of detailed graphs showing project performance in decline - adding fuel to the fire of business uncertainty and further amplifying an out-of-control spiral into the depths of failure. An antidote to administrative burden is enabling leadership.

\section{ENABLING LEADERSHIP}

Ultimately, there needs to be a balance in leadership stylesomething along a good-cop, bad-cop pairing — where both administrative and enabling leadership complement each other to achieve mutual goals. Enabling leadership acts as the goodcop in this leadership scenario, leveraging the team's intellectual capital. High levels of discussion, mentoring, collaboration, and clarification are needed in this style. These activities are used to explore options, seek optimal solutions, encourage teamwork, spark innovation, and ensure that there is clarity of context (see Fig. 2).

Enabling leaders share leadership tasks with the team to best use local skills, knowledge and experience. They tend to build team spirit and grow engagement, even excitement, steering the flow of team activities with minimal dictating. Through discussion, they see areas where there is uncertainty, and gaps in knowledge, sniffing out poorly allocated tasks and miscommunication. They seek to fill these gaps by reallocating work or by gaining wider consensus on solutions. While this approach may seem optimal — an almost heroic leadership style - it must be balanced with administrative leadership - often viewed as the bad-cop in this leadership scenario. When enabling leaderships becomes too dominant, there can be a lack of directed progress and focus. Taken to an extreme, enabling leadership alone can damage the team's reputation as they are perceived as pursuing "pet projects" or "turning simple tasks into a $\mathrm{PhD}$ " rather than delivering on business commitments. When well-balanced, enabling leadership can deliver the appropriate innovation needed to solve technical challenges. It can also deliver innovative approaches to project and process management that increases productivity, deconstructing complex tasks into simple, achievable ones. An engaged and highly collaborative team will always out-perform a disengaged and siloed one.

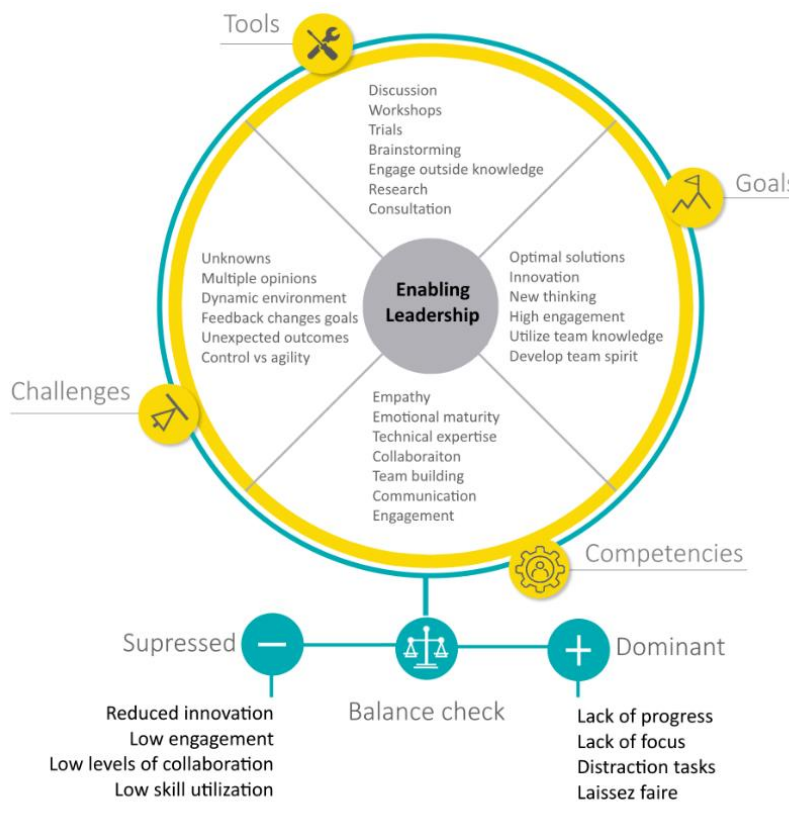

Fig. 2 Enabling Leadership Model

\section{ADAPTIVE LEADERSHIP}

The final leadership style, although important, should rarely be needed. Adaptive leadership is required for managing unplanned emergent events, often described as "fire-fighting". When the unexpected happens and the project becomes derailed, the ability to get a group together and generate a rapid countermeasure is invaluable. Adaptive Leadership is short-term and, in the main, operates outside of process (see Fig. 3). Adaptive leadership should be non-heroic. It should be a collaborative endeavor where new ideas are quickly

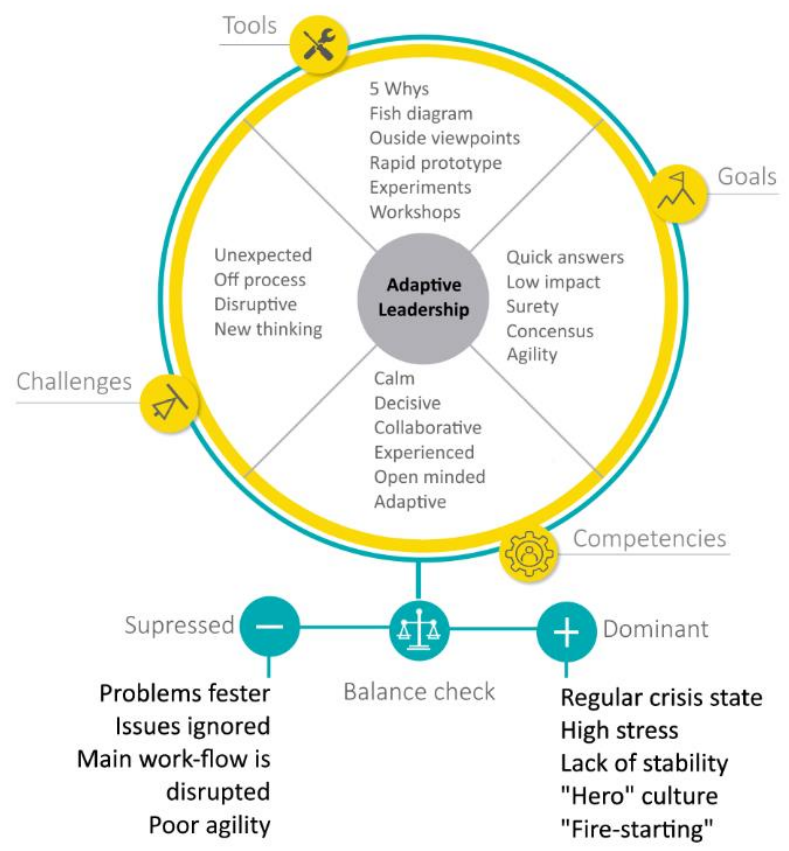

Fig. 3 Adaptive Leadership Model 
generated and evaluated by a highly energized, experienced, and creative team. If the combination of administrative and enabling leadership is working as planned, there should be few occasions which require adaptive leadership. Adaptive leadership should only be needed if it is critical for continued project viability. It might seem that adaptive leadership is unlikely to be taken to an extreme. Yet the rewards for a leader who heroically saves the project from jeopardy can be disproportionately large in comparison to rewards given to a leader who calmly delivers without drama. In such a potentially perverse managerial environment, leaders are effectively rewarded for allowing fires to break out and an artificial state of emergency can become the norm. This situation is very stressful for the team causing inefficiencies and a cycle of reactive fire-fighting.

\section{CONCLUSION}

KPIs can help practicing managers track complex endeavorssuch as engineering projects - allowing them to reduce such complexity to simple and comparable parameters. They are indicators of performance, but they do not give an understanding of performance. KPIs need to be used in conjunction with a functional leadership framework to deliver success. CLT works within organizations formed of complex systems - engineering projects is one such complex system. CLT also recognizes and promotes the mechanisms of innovation which are critical to engineering. In this article, we have provided insight into this complex system management through a leadership model which is backed by science and the weight of experience. For example, we know that wildly unexpected things happen-such as financial crashes, the collapse of industry giants of industry - and that our best laid plans can unravel. These plans are also subject to constant adjustment from conception to delivery. These situations are symptomatic of complex system behavior.

CLT proposes quite simply that, if you want to lead complexity, you need to use a leadership model which acknowledges and responds to the nature of complexity. We also raise awareness in this article, that no single style of leadership should dominate, that there needs to be balance and leadership balance checks. Finally, we provide some examples of these situations where balance is needed in leadership, however many more examples exist.

\section{REFERENCES}

[1] D. A. Bishop, "Key performance indicators: Ideation to creation," IEEE Engineering Management Review, vol. 46, no. 1, pp. 13-15, 2018.

[2] J. Meredith and O. Zwikael, "When is a project successful?," IEEE Engineering Management Review, vol. 47, no. 3, pp. 127-134, 2019.

[3] D. White and J. Fortune, "Current practice in project management-An empirical study," International journal of project management, vol. 20, no. 1, pp. 1-11, 2002.

[4] M. Uhl-Bien, R. Marion, and B. McKelvey, "Complexity Leadership Theory: Shifting leadership from the industrial age to the knowledge era," The Leadership Quarterly, vol. 18, no. 4, pp. 298-318, 2007, doi: 10.1016/j.leaqua.2007.04.002.
Chris Biggadike Studied Product Design at Chelsea School of Art and was then awarded a BSc Hons. in Mechanical Engineering from the Open University and an MSc in Engineering Management from The University of South Wales. He is a Chief Engineer with Ultra Electronics and a Doctoral Researcher at Brunel University London where his research focuses on the application of complexity leadership theory in engineering organizations. Mr. Biggadike is a Chartered Engineer and a member of the IET.

Richard Evans received his Ph.D. degree in enterprise social software from the University of Greenwich, London, U.K., in 2013. He is Associate Professor in Digital Innovation within the Faculty of Computer Science at Dalhousie University, Canada, where he also acts as Program Director for Bachelor of Applied Computer Science. Richard is an established academic with research, teaching and supervision experience in the fields of digital innovation and transformation, design and engineering management, and entrepreneurship. He has authored/coauthored numerous papers in peer-reviewed journals, including Technological Forecasting and Social Change, IEEE Transactions on Engineering Management, Computers in Human Behavior, and the International Journal of Production Research.

Eujin Pei is Associate Dean for the College of Engineering, Design and Physical Sciences at Brunel University London and the Director for the BSc Product Design Engineering programme. He is a Chartered Engineer (CEng), Chartered Environmentalist (CEnv) and a Chartered Technological Product Designer (CTPD). He is the Editor-in-Chief for the Progress in Additive Manufacturing Journal. 